\title{
Role of laparoscopic surgery in cancer of stomach: Our early experience
}

\author{
Rajinder Kumar Chrungoo', Tariq Ahmed Mala1, Rahul Gupta², Shadi Lal Kachroo², Inakshi Chrungoo , \\ Shahid Amin Malla ${ }^{3}$ \\ ${ }^{I}$ Department of Surgery, ASCOMS Jammu, Jammu And Kashmir (J\&K), India \\ ${ }^{2}$ Department of Surgery, Government Medical College, Jammu, India \\ ${ }^{3}$ Department of Medicine \& Surgery, Government Medical College, Jammu, India
}

Received April 23, 2015; Revised June 24, 2015; Accepted June 26, 2015; Published Online August 11, 2015

\section{Original Article}

\begin{abstract}
Purpose: To study the clinical outcome and scope of laparoscopic management in patients of cancer stomach. Methods: This is a prospective study of our first 25 patients of cancer stomach managed laparoscopically. Following procedures were undertaken: 1) Gastric resection in resectable cases; 2) Palliative bypass; 3) Tumor/ nodal/ peritoneal/ any other/ biopsy in cases of unresectable tumors. Results: Growth was resectable in $10(40 \%)$ patients, and unresectable in 15 (60\%) patients. Diagnostic laparoscopy had sensitivity of $100 \%$, while other modalities of investigation were not totally useful in $1 / 3$ to $1 / 2$ of cases. Laparoscopic gastrojejunostomy was done in 5 (20\%) patients, laparoscopy assisted distal partial gastrectomy was performed in 8 (32\%) patients while totally laparoscopic gastrectomy was possible in $1(4 \%)$ patient. Long term follow up was observed. Conclusion: In cancer stomach laparoscopy is a safe, effective, and cost effective means of directing appropriate therapy especially in patients requiring diagnostic, staging and palliative procedures.
\end{abstract}

Keywords: Diagnostic Laparoscopy; Laparoscopic Gastrojejunostomy; Laparoscopic Gastrectomy; Unresectable Tumors; Palliation; Laparoscopic Biopsy

\section{Introduction}

Gastric cancer is one of the leading causes of death from malignant diseases in India (Nandakumar et al.). ${ }^{1}$ It was Kitano et al. ${ }^{2}$ who first described treatment for early gastric cancer by laparoscopy-assisted distal gastrectomy (LADG). Gastric resection with D1 lymphadenectomy with no residual neoplasm remains the gold standard treatment for cancer stomach, as it is the only treatment modality offering the possibility of cure for these patients. $3,4,5,6$ Correct staging is a prerequisite for the optimal treatment. Despite an increasingly sophisticated diagnostic armamentarium many patients with gastric malignancy continue to have the diagnosis of unresectable or metastatic disease made at exploratory laparotomy. Laparoscopic surgery is sensitive for staging gastric cancer especially identifying tumor deposits that cannot be detected by conventional imaging. ${ }^{7}$ It can thus prevent open surgery in patients with inoperable disease. Gastric outlet obstruction is a common and often preterminal event for patients with inoperable neoplasms of the distal stomach. Palliative laparoscopic gastric bypass is best that can be done for such patients.

The objective of this study is to assess the role of laparoscopy in gastric malignancies in our setup with the changing trends of treatment without compromising the surgical principles and maintaining high standards of patient care.

\section{Methods and Materials}

Follow up of our first of 25 patients of cancer of stomach who were managed laparoscopically is presented. A detailed work up was carried out and recorded on a proforma. A written informed consent was taken from every patient. Preoperative preparation was carried out by giving bowel washes 24-48 hours before surgery. The patients were placed in a reverse Trendelenburg position.

In earlier cases the surgeon stood on the right side of the patient at the start of surgery, and during dissection of the infrapyloric lymph nodes moved to the left side of the patient, later the most comfortable situation was seen to be standing in between the legs. Carbon dioxide $\left(\mathrm{Co}^{2}\right)$ pneumo peritoneum of $15 \mathrm{~mm} \mathrm{Hg}$ was created by using closed Veress needle technique as a uniform standard procedure. $10 \mathrm{~mm} 0^{\circ}$ laparoscope (later on $30^{\circ}$ ) was introduced through the infraumblical port. Working ports were made in the right and left lumbar regions, right and left

Corresponding author: Tariq Ahmed Mala; Department of Surgery, ASCOMS Jammu, Jammu And Kashmir (J\&K), India.

Cite this article as: Chrungoo RK, Mala TA, Gupta R, Kachroo SL, Chrungoo I, Malla SA. Role of laparoscopic surgery in cancer of stomach: Our early experience. Int J Cancer Ther Oncol 2015; 3(3):3320. DOI: 10.14319/ijcto.33.20 
sub-costal regions. Additional ports were placed for retraction of liver and stomach and wherever needed. The abdomen was surfed thoroughly for growth, abdominal viscera, nodes metastasis and for ascitis. Following procedures were undertaken: 1) Gastric resection in resectable cases; 2) Palliation by bypass procedures with or without biopsies, ascetic sampling; 3) Tumor/nodal/peritoneal /any other biopsy in case of unresectable tumors, not amenable to palliative bypass procedures.

The dissection was carried out by diathermy and ultrascission. The transaction and anastomosis was carried out by 45 $\mathrm{mm}$ and $65 \mathrm{~mm}$ endostaplers and Circular and linear cutter staplers. The specimens were inserted into a retrieval bag, withdrawn through the $10 / 12 \mathrm{~mm}$ port widened to accommodate. Specimen orientation was done by sutures and was sent for histopathological examination. The extracorporeal anastomosis also were done using window.

\section{Results}

There were $19(76 \%)$ males as against females 6 (24\%). Males: Female ratio was 3.17:1. The youngest patient was 30 years old female and oldest was 84 years old male. The mean age was 59.8 years. The highest incidence was in the 51-70 years (72\%). Out of 6 females 4 were in the age group of 21-40 years. Cancer stomach was seen in younger age group among females. Pain was the predominant symptom in 14 (56\%) of patients despite the fact that dyspepsia and sour eructations were the commonest symptom. Pain was followed by anorexia (12\%) and vomiting $(8 \%)$ as the predominant symptom. Though pain was present in 18 (72\%) patients, pain associated with vomiting was seen in 15 patients (60\%), while the combination of pain, vomiting, weight loss was present in 13 patients (52\%), and the combination of pain, vomiting, anorexia, weight loss was seen in 12 patients $(48 \%)$ patients.

The site of pain was epigastrium in 16 patients, while 2 patients presented with pain in the right hypochondrium. The radiation of pain was seen in 4 patients. The character of pain was burning in 11 and dull ache in 6 patients. The stabbing pain was present in 1 patient; change in character of pain was seen in 4 patients. At the mean duration of pain was 7.4 months. The mean duration of symptoms were 7.34 months. Anemia was the most common co morbid condition accounting for $16(64 \%)$ cases, followed by COPD in 6 (24\%).

One patient had gastrojejunostomy done for peptic ulcer 20 years back. 3 patients (12\%) had history of gastric ulcer while 1 had duodenal ulcer and 2 had history of removal of gastric polyps. All patients were non-vegetarians, 12 (48\%) were alcoholic, 18 (72\%) were smokers, 7 (28\%) were nonsmokers. Blood group $\mathrm{A}^{+\mathrm{ve}}$ was the most common being pre- sent in 11 (44\%), followed by $\mathrm{O}^{+\mathrm{ve}}$ which was seen in 7(28\%). Site of carcinoma of stomach was distal one third in $15(60 \%)$ patients, proximal one third in $3(12 \%)$ patients, middle one third in 2 (8\%) and diffuse involvement was seen in 5 (20\%) patients [Table 1].

Regional metastasis was present in $6(24 \%)$ patients; perigastric lymph nodes were present in 17 (68\%) patients, ascitis in $10(40 \%)$ patients. Intraoperative complications were present in $7(28 \%)$ patients $1(4 \%)$ patient had intra operative hemorrhage while 6 (24\%) had technical complications. Post-operative complications were present in 11 (44\%).

TABLE 1: Showed demographic details.

\begin{tabular}{|c|c|c|}
\hline Predominant symptom & Number of patients & Percentage (\%) \\
\hline \multicolumn{3}{|c|}{ Sex } \\
\hline Males & 19 & $76 \%$ \\
\hline Females & 6 & $24 \%$ \\
\hline Pain (predominant symptom) & 14 & $56 \%$ \\
\hline \multicolumn{3}{|c|}{ Site of growth } \\
\hline \multicolumn{3}{|c|}{ (Diagnostic laparoscopy) } \\
\hline Proximal $1 / 3$ & 3 & $12 \%$ \\
\hline Middle $1 / 3$ involving pylorus & 2 & $8 \%$ \\
\hline Distal 1/3 & 15 & $60 \%$ \\
\hline Diffuse involvement & 5 & $20 \%$ \\
\hline \multicolumn{3}{|c|}{ Extent of growth } \\
\hline Perigastric lymphadenopathy & 17 & $68 \%$ \\
\hline Regional lymphadenopathy & 6 & $24 \%$ \\
\hline Ascites & 10 & $40 \%$ \\
\hline $\begin{array}{l}\text { Moderately differentiated } \\
\text { adenocarcinoma stomach }\end{array}$ & fistopathology & $80 \%$ \\
\hline $\begin{array}{l}\text { Poorly differentiated adeno- } \\
\text { carcinoma stomach }\end{array}$ & 5 & $20 \%$ \\
\hline
\end{tabular}

Diagnostic laparoscopy had sensitivity of $100 \%$, while other modalities of investigation missed $1 / 3$ to $1 / 2$ of cases. Endoscopy had a sensitivity of $64.28 \%$, while endoscopic biopsy was having sensitivity of only $28.57 \%$. Growth was resectable in $10(40 \%)$ patients, while in $15(60 \%)$ it was unresectable [Table 2], [Figures 1, 2].

\section{Long term results}

Of the total 25 patients, $20(80 \%)$ were followed up and 5 were lost to follow-up. Follow-up data were available for 20 $(80 \%)$ of patients treated laparoscopically. The mean follow-up was 60 months (range 6-72 months).

In the follow up 3 (15\%) patients experienced recurrence and died due to the disease within 12 months. Two patients are still alive at 70 months after surgery. Five patients died at 14 months and 9 patients died at 18 months and one patient died in the immediate postoperative period. 
TABLE 2: Showed various procedures done.

\begin{tabular}{lc}
\hline \hline \multicolumn{1}{c}{ Procedure done } & Number of patients \\
\hline Diagnostic laparoscopy and biopsy/ascetic sampling & $4(16 \%)$ \\
Diagnostic laparoscopy followed by laparoscopic gastrojejunostomy & $5(20 \%)$ \\
Diagnostic laparoscopy followed by laparoscopy converted into open gastrojejunostomy & $6(24 \%)$ \\
Diagnostic laparoscopy followed by laparoscopic gastrectomy with perigastric lymphadenectomy & $1(4 \%)$ \\
$\begin{array}{l}\text { Diagnostic laparoscopy followed by laparoscopy converted into open oesophagogastrectomy with } \\
\text { perigastric lymphadenectomy }\end{array}$ & $1(4 \%)$ \\
$\begin{array}{l}\text { Diagnostic laparoscopy followed by laparoscopic partial gastrectomy with perigastric lymphadenec- } \\
\text { tomy with trans thoracic oesophagogastrectomy }\end{array}$ & $1(4 \%)$ \\
$\begin{array}{l}\text { Diagnostic laparoscopy followed by laparoscopy assisted partial gastrectomy with peri gastric lym- } \\
\text { phadenectomy }\end{array}$ & $6(24 \%)$ \\
Diagnostic laparoscopy followed by laparoscopy assisted total gastrectomy with peri gastric lym- \\
phadenectomy with oesophagojejunostomy
\end{tabular}

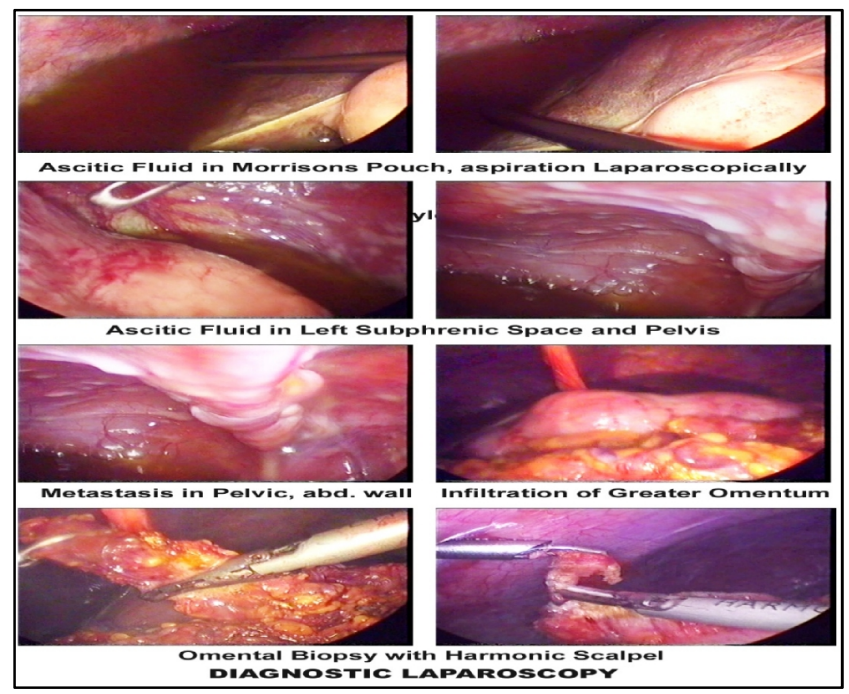

FIG. 1: Showing various findings on diagnostic laparoscopy.

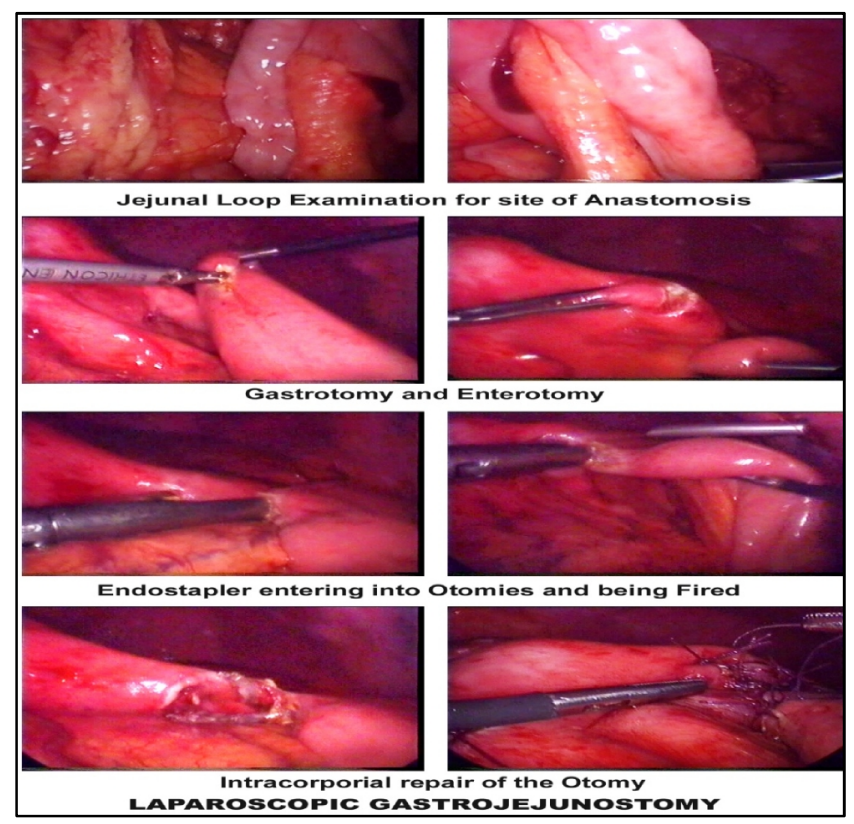

FIG. 2: Showing site of gastrojejunostomy with intracorporial repair.

\section{Discussion}

Generally extent of surgery was determined by tumor stage, tumor location, and histological type, according to Lauren classification, quality of life, age and expected survival. Few randomized clinical trials $3,4,5,6$ have compared open distal gastrectomy versus laparoscopic operation, in which the entire dissection is conducted laparoscopically, followed by specimen removal through small incision in epigastrium and Billroth I reconstruction. In our cases the critical questions of important clinical consequences for the outcome of the patient with advanced but potentially curable gastric cancer are among the following options: (1) Subtotal vs. total gastrectomy; (2) spleen preservation vs. splenectomy; (3) preservation of pancrease vs. left sided pancreatectomy; (4) limited D1 vs. extended D2/D3 lymphadenectomy.

Total gastrectomy is the procedure of choice for tumors located in the proximal or middle third of the stomach, advanced intestinal type carcinoma and for all carcinomas categorized as diffuses according to the Lauren classification. For antral cancers, subtotal gastrectomy with the advantage of better quality of life and a low morbidity. ${ }^{8}$ Griffith et al. ${ }^{9}$ suggest that indications for splenectomy are (1) direct invasion of the spleen through serosa and (2) enlarged suspected hilar lymph nodes.

The well documented significant adverse effect of pancreatectomy on morbidity and mortality and the available histological and survival data make it clear that the only indication for this procedure is direct invasion of the pancreas by the tumor through the gastric serosa, however resection of the distal pancreas has proved to be very dangerous. ${ }^{10}$ Some studies have described the disadvantages of laparoscopic assisted distal gastrectomy compared to open distal gastrectomy, which include increased operative time similar to that in our study. ${ }^{11-14}$ The most and at the same time, controversial topic in the surgical management of gastric carcinoma is the extend of lymphadenectomy. D2/D3 resection has been performed for more than 30 years in Japan, but the therapeutic benefit of this procedure still remains debatable. According to the JRSGC (Japanese Research Society for Gastric 
Cancer) guidelines, the upper abdominal lymph nodes are grouped into 16 stations, which are subsequently divided into four levels (NI-N4) according to the location of the primary tumor. ${ }^{15}$ The extent of the lymphadenectomy is classified according to the level of lymph node dissection (D1 to D2). On the basis of these reasons we decide to go for subtotal /total gastrectomy, spleen preservation and preservation of the pancreas with limited D1/D2 resection.

Of the various procedures performed in our study, palliation was the most common and was done in the form of gastrojejunostomy. Mostly laparoscopic gastrojejunostomy was done in $5(20 \%)$ patients. In $6(24 \%)$ patients conversion into open was done to complete the procedure. Diagnostic laparoscopy avoided laparotomy in $4(16 \%)$ and was better in accurately assessing the serosal infiltration, peritoneal seeding, and metastasis and allowed the surgeon to choose more effective treatment modality. According to Burke et al. ${ }^{16}$ laparoscopy avoided laparotomy in $23.1 \%$ cases, Molloy et al. 17 in $42.2 \%$ cases.

In our study intraoperative complications occurred in 7 (28\%) patients. $1(4 \%)$ patient had intraoperative hemorrhage, bleeding from the left gastric artery, 6 (24\%) patients had technical complications in the form of instrumentation failure.

Post-operative complications were seen in 11 (44\%) cases. In all the cases of postoperative, wound infection were present $4(16 \%)$, it was preceded by seroma formation $9(36 \%)$.

One patient in the laparoscopy Assisted gastrectomy group, on $4^{\text {th }}$ postoperative day, started pouring bile from the drain kept in the right paracolic gutter. This drainage stopped spontaneously within another five days with no evidence of continuous or residual leak. No patient developed complications related to pneumoperitoneum or anesthesia or the ones like pancreatitis, pleural effusion, dumping syndrome, intrabdominal abscess or external bleeding.

In our study the percentage of conversion into open surgery taking into account all the procedures was $28 \%$ compared to $1-2 \%$ reported by Gemmill et al. ${ }^{18}$ The two studies are not comparable as the total number of cases in our series is very low. Mean operating time, mean intraoperative blood loss, pain, mean analgesic doses, mean time to pass flatus, time to start liquid diet (resumption of diet), time to become fully mobile was least in case of laparoscopy group. Mean postoperative hospital stay was lesser in those who underwent laparoscopic gastrojejunostomy than others [Table 3]. Our results were similar and sometimes better than a number of studies conducted all over the world especially in the west Pugliese et al. ${ }^{19}$, Dulucq et al. ${ }^{20}$, Adachi et al. ${ }^{21}$, Sakuramoto et al. ${ }^{22}$
Histologically the growth was moderately differentiated adenocarcinoma in 20 (80\%) patients and poorly differentiated adenocarcinoma stomach in 5 (20\%). The margins of resection were 4-6 cm and these were found to be free of tumor. Of total patients 8 (32\%) were in T2 N0 M0, 2 (8\%) patients in stage T2 N1 M0 and $15(60 \%)$ patients were in T4 NX M0/M1 stage. In our study lymph node metastasis was seen in $20 \%$ of the patients who underwent gastrectomy while lymph node metastasis was absent in $80 \%$ of cases which corresponds to the study done by Kitano et al..$^{22}$ Condition on discharge in 20 (80\%) patients was satisfactory.

In all the patients in whom growth was unresectable and palliative laparoscopic gastrojejunostomy was performed were tolerating oral diet reasonably well and their agonies were less and recovery was faster as compared to the open group. All the patients were followed up for 3 weeks after discharge and all of them in the laparoscopy group were doing reasonably far better than the open group except for one patient who underwent laparoscopic gastrojejunostomy was readmitted for gross ascitis.

Postoperative mortality was present in 1 (4\%) patient (within 1 week from the discharge). In the study done by Gemmil et al. ${ }^{18}$ who studied 2546 patients, postoperative mortality was $0.1 \%$ of cases. The difference in value was due to our small sample size.

\section{Conclusion}

Our experience suggests that laparoscopy is a safe, effective and cost-effective means of directing appropriate therapy and avoiding unnecessary exploration. Laparoscopy plays an extremely valuable role in staging of patients with gastric malignancy. Palliative laparoscopic gastric bypass in comparison to open bypass has less operation time, significantly less intraoperative blood loss and least incidence of wound infection.

Laparoscopy assisted gastrectomy, when compared with conventional open gastrectomy, has several advantages, including less surgical trauma, less pain, rapid return of gastrointestinal function, less impaired nutrition, and shorter hospital stay, with no decrease in operative curability. When performed by a skilled surgeon, laparoscopic assisted gastrectomy is safe, useful and curative technique for patients with gastric cancer. Compared to conventional surgery, it offers the advantages of low invasiveness and improved quality of life. Lastly there are definite benefits of laparoscopy in diagnosis, staging and palliation in case of carcinoma stomach. 


\section{Conflict of interest}

The authors declare that they have no conflicts of interest. The authors alone are responsible for the content and writing of the paper.

\section{References}

1. Nandkumar A, Dhar M. Five year consolidated report of the hospital based cancer registries 1994-1998. National Cancer Registry Programme. 2002; 1:4-18.

2. Kitano S, Iso Y, Moriyama M, Sugimachi K. Laparoscopy-assisted Billroth I gastrectomy. Surg Laparosc Endosc. 1994;4:146-8.

3. Kitano S, Shiraishi N, Fujii K, et al. A randomized controlled trial comparing open vs laparoscopy-assisted distal gastrectomy for the treatment of early gastric cancer: An interim report. Surgery. 2002;131:S306-11.

4. Hayashi H, Ochiai T, Shimada H, Gunji Y. Prospective randomized study of open versus laparoscopy-assisted distal gastrectomy with extraperigastric lymph node dissection for early gastric cancer. Surg Endosc. 2005;19:1172-6.

5. Kim HH, Hyung WJ, Cho GS, et al. Morbidity and mortality of laparoscopic gastrectomy versus open gastrectomy for gastric cancer: An interim report--a phase III multicenter, prospective, randomized Trial (KLASS Trial). Ann Surg. 2010; 251: 417-20.

6. Lee JH, Han HS. A prospective randomized study comparing open vs laparoscopy-assisted distal gastrectomy in early gastric cancer: Early results. Surg Endosc. 2005;19: 168-73.

7. Brady PG, Peebles M, Goldschmid S. Role of laparoscopy in the evaluation of patients with suspected hepatic or peritoneal malignancy. Gastrointest Endosc. 1991; 37:27-30.

8. Roukos DH. Current advances and changes in treatment strategy may improve survival and quality of life in patients with potentially curable gastric cancer. Ann Surg Oncol. 1999;6:46-56.

9. Griffith JP, Sue-Ling HM, Martin I, et al. Preservation of spleen improves survival after radical surgery for gastric cancer. Gut. 1995; 36: 684-90.

10. Cuschieri A, Fayers P, Fielding J, et al. Postoperative morbidity and mortality after D1 and D2 resection for gastric cancer: preliminary results of the $\mathrm{MRC}$ randomized controlled surgical trial. The
Surgical Cooperative Group. Lancet. 1996; 347: 995-9.

11. Kim YW, Baik YH, Yun YH, et al. Improved quality of life outcomes after laparoscopy-assisted distal gastrectomy for early gastric cancer: results of a prospective randomized clinical trial. Ann Surg. 2008; 248:721-7.

12. Hwang SI, Kim HO, Yoo CH, et al. Laparoscopic-assisted distal gastrectomy versus open distal gastrectomy for advanced gastric cancer. SurgEndosc. 2009; 23: 1252-8.

13. Han JH, Lee HJ, Suh YS, et al. Laparoscopy-assisted distal gastrectomy compared to open distal gastrectomy in early gastric cancer. Dig Surg. 2011; 28: 245-51.

14. Chun HT, Kim KH, Kim MC, Jung GJ. Comparative study of laparoscopy-assisted versus open subtotal gastrectomy for pT2 gastric cancer. Yonsei Med J. 2012; 53: 952-9.

15. Kajitani T. The general rules for the gastric cancer study in surgery and pathology. Part I. Clinical classification. Jpn J Surg. 1981;11:127-39.

16. Burke EC, Karpheh MS, Conlon KC. Laparoscopic in the management of Gastric adenocarcinoma. Ann Surg. 1997;225:262-7.

17. Molloy RG, McCourtney JS, Anderson JR. Laparoscopy in the management of patients with cancer of the cardia and oesophagus. Br J Surg. 1995; 82:352-4.

18. Gemmill EH, McCulloch P. Systemic review of minimally invasive resection for GE cancer. Br J Surg. 2007; 94: 1461-7.

19. Pugliese R, Maggioni D, Sansonna F, et al. Outcomes and survival after laparoscopic gastrectomy for adenocarcinoma. Analysis on 65 patientsoperated on by conventional or robot-assisted minimal access procedures. Eur J Surg Oncol. 2009;35:281-8.

20. Dulucq JL, Wintringer P, Stabilini C, et al. Laparoscopic and open gastric resection for malignant lesions: a prospective comparative study. Surg Endosc. 2005; 19:933-8.

21. Adachi Y, Shiraishi N, Shiromizu A, et al. Laparoscopy -assisted Billroth I gastrectomy compared with conventional open gastrectomy. Arch Surg. 2000; 135:806-10.

22. Kitano S, Shiraishi N, Fujii K, et al. A randomized controlled trial comparing open vs laparoscopy-assisted disral gastrectmy for the treatment of early gastric cancer: an interim report. Surgery. 2002; 131:306-11. 